\title{
The Influence of Family Factors on Adolescent Depression
}

\author{
Yiran Du
}

The Experimental High School Attached to Beijing Normal University

*Corresponding author.Email: anniedyr@126.com

\begin{abstract}
Adolescent mental health is one of the major public health issues, and depression among contemporary adolescents is increasing year by year. According to data released by the World Health Organization in 2019, the total number of depression cases worldwide exceeds 350 million, and about 200,000 people commit suicide each year due to depression. Family life occupies a large part of the life of adolescents, so family factors have a great influence on adolescent depression. This paper systematically summarizes the research progress between various family factors such as socioeconomic status, parent-child relationship conflict, family dysfunction, triggering of early traumatic experience experiences and common psychological problems of adolescents, which are basically divided into two categories of positive and negative correlations to provide theoretical basis and research clues for solving adolescent psychological problems.

In many families, the parents' long-term lack of understanding, excessive control or attention causes the child's selfneeds to conflict with the parents' demands, resulting in the child's inability to vent his or her emotions and a sense of helplessness and suffocation. In this regard, this paper also summarizes and analyzes several countermeasures to help adolescents to stay away from psychological problems or to help those who have already suffered from depression to stay away from the haze of depression better and faster.
\end{abstract}

Keywords: Adolescent depression, mental health, family.

\section{INTRODUCTION}

There is a wealth of research in the field of adolescent depression and systematic responses to it. However, there are still many families whose children suffer from depression or depressive moods because of the social stigma of depression and the high expectations that some parents place on their children in an internalized environment to the point of reaching an almost pathological state of mind.

The purpose of this paper is to analyze in detail the various family factors that lead to depression in adolescents and their countermeasures, to make predictions for different situations and to prevent them rationally, and to suggest different ways to minimize depression in adolescents for different factors. The specific question studied in this paper is the family factors (endogenous \& exogenous) that contribute to depression in adolescents. This paper uses literature survey method, behavioral research method, observation method, and discernment method. This study can systematically enumerate, summarize, and analyze ways to cope with depression in adolescents and make improvements to the grim status quo.

\section{ANALYSIS OF FAMILY FACTORS THAT CAUSE DEPRESSION IN ADOLESCENTS AND THEIR SOLUTIONS}

\subsection{The external factors}

\subsubsection{The socio-economic status}

According to the FSM(Family Stress Model), family economic pressure will increase parents' emotional or behavioral problems and have a negative impact on parents' parenting behavior, thus having a negative impact on teenagers' emotional or behavioral problems[1]. 


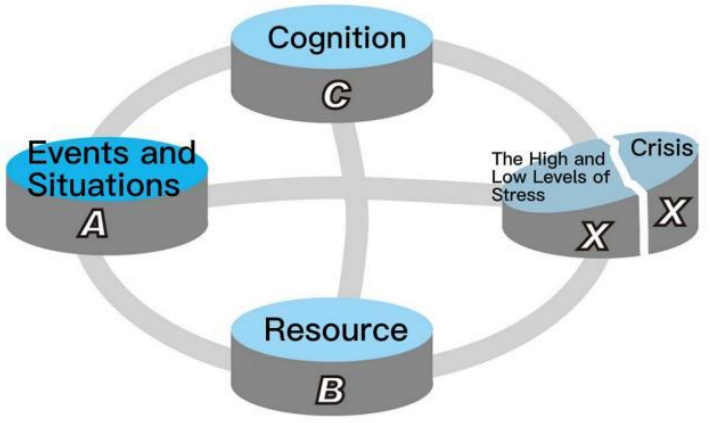

Figure 1 Family Stress Model
The family stress model is shown in the figure, where A represents the stressor event, B represents the family's resources, $\mathrm{C}$ represents the perception of the event, and $\mathrm{X}$ represents the outcome (i.e., the level of stress that results, high $=$ stress; low $=$ management or crisis). evaluation[2].

According to the FIM(Family Investment Model), parents of adolescents with high socioeconomic status have more time to participate in their children's lives, which can provide them with richer learning activities and better parenting methods, thus having a positive impact on adolescents' emotional or behavioral problems.

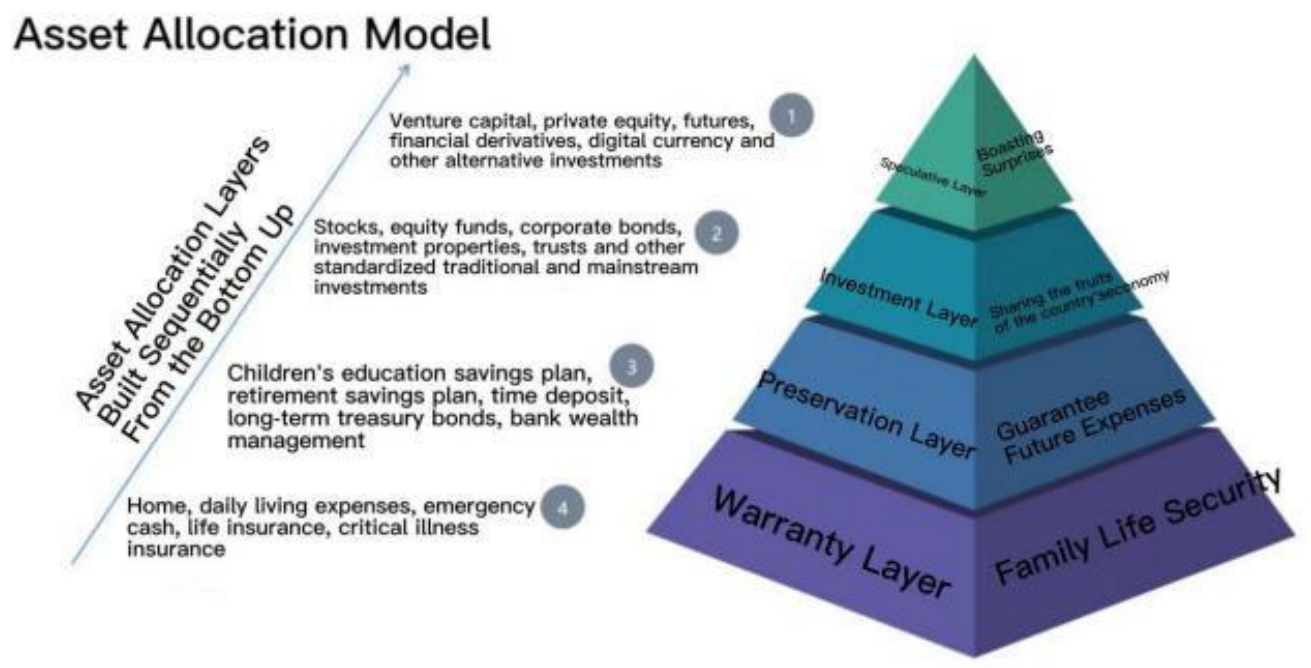

Figure 2 Asset Allocation Model [3]

The family investment model (FIM) is shown in the figure. The bottom layer is the protection layer, which is the most basic asset allocation and is responsible for protecting family life; the top layer is the speculative layer, which represents various financial products for family investment; the second layer is the investment layer, which represents the mainstream investment varieties such as stocks. And the third layer is the preservation layer, which is the most important part of the whole family SES allocation, which contains savings and deposits for children's education - this layer is also the most important part of this paper in terms of its impact on the family's socio-economic status.

If the socio-economic status of the family is higher, the parents will be able to provide a better material environment for the child, and the relationship between the two parents will not be rifted because of financial issues. If the opposite is true, then the child will have an inferiority complex because of some material inadequacy, or negative emotions and moods because of the parents' arguments about financial conditions.

\subsubsection{The over-expectations and pressure from parents}

Over-expectation

\section{High pressure}

Most parents pay more attention to their children's academic performance and have higher expectations. When children fail to meet their parents' expectations and get no recognition from their parents, they will have a sense of uselessness and low self-worth, which ultimately leads to despair[4].

The vast majority of children care about exam scores or rank in the class very much and bear a lot of exam pressure, while some parents like to compare their children with other children in the environment.

These two kinds of problem are significant in the high school student population. Because of the pressure to advance to higher education, parental expectations put especially more pressure on children. The social environment has also become increasingly high-pressure in recent years, with various waves of involution, in which parents and children are not immune.

According to China Youth Daily, August 31, 2020, attending extracurricular classes is not a new topic at all for current Chinese students. As early as four years ago, the "Survey Report on the Current Situation of China's Tutoring Education Industry and Tutoring Institution Teachers" released by the Chinese Education Society 
disclosed that the market size of China's primary and secondary school extracurricular tutoring industry has exceeded 800 billion yuan, with more than 137 million students participating[5]

Such a huge scale of participation in extracurricular classes (and other institutions that invariably increase the pressure on children to study) makes the psychological problems of teenagers more and more severe. Not only are parents anxious about their children's studies, but teenagers are also pressured by parental expectations and high-pressure learning environments, which can lead to psychological problems. According to a poll conducted by Southern Metropolis Daily at the end of 2020, more of the students surveyed showed psychological distress such as loss of self-control, lowered self-esteem and alienation from family and friends, and elimination of social interaction as the grade level increased. The percentages of students with self-control in elementary, middle and high school were $15.40 \%, 18.40 \%$ and $32.30 \%$, respectively; the percentages of students with lowered self-esteem were $7.70 \%, 21.10 \%$ and $38.70 \%$, respectively; and the percentages of students with alienation from friends and relatives and social inhibition were $0.00 \%, 21.0 \%$ and $25.8 \%$, respectively, which showed a gradual increase with grade level[6].

\subsubsection{Family conflict}

\section{Excessive parental control}

Parents do not understand, excessive control or attention for a long time, resulting in children's own needs and parents' requirements conflict, resulting in children's emotions cannot vent, helpless and suffocating feeling.

Researchers at the University of Mary Washington found that college students were more likely to be depressed or dissatisfied if they had controlling parents.

So-called "helicopter parenting" refers to parents who over involve themselves in their child's lives. The study found that that style of parenting may leave kids feeling less competent and less able to manage their own affairs than those children who were more independent, said ANI. It looked at 297 American undergrads between the ages of 18 and 23. The young adults took surveys asking them questions about the parenting style they were raised with[7].

When children were also asked to rate themselves on competitiveness, anxiety, depression, life satisfaction, and other categories, children who had been overly controlled by their parents were more depressed, anxious, and had difficulty getting along with others. Research suggests that excessive parental involvement interferes with the natural development of children's autonomy.

Parents conflict
Conflict in the relationship between husband and wife due to differences in values or behavioral habits leads to tension and chaos in the family, full of tension, and the family loses the warmth and comfort it should have. In the long run, children cannot feel the warmth of the family and the support of their parents, resulting in a loss of intimacy and security.

When children are born, it is the relationship between parents that shapes their sense of family the most. Traditionally, "family" has been likened to a "haven of happiness". But often, this is not the case. If the parents' relationship is very strained, or if there are cracks in the relationship caused by extramarital affairs, domestic violence, and other kinds of bad relationships, then the child will also be affected. The specific manifestations may be a loss of security in the family, more likely to fall into aberrant intimate relationships when they grow up, and so on. In adolescence, the most significant manifestations are depression, anxiety, and even psychological distortion[8].

\section{Parent-child conflict}

Parents always communicate with their children in a didactic manner from their own point of view or in a strong position, and rarely empathize with them from their children's perspective. The lack of effective interaction between the child and the parents makes the child feel unappreciated and unrespected, creating a deep sense of despair.

If parents demand - or even force - their children to do things from their own point of view, it is easy to create conflicts between parents and children. The child may feel that he or she cannot communicate with the parent, but cannot resist, and may feel irritated by this, to the point where psychological problems arise.

This conflict is especially likely to occur during the adolescent years of children. During this period, adolescents' physical development is very rapid. Their physiological maturity makes them want to gain the same rights as adults psychologically, and they are eager to be independent and free from parental control; however, at the same time, their psychological development lags behind, with weak self-control, lack of rational thinking, and immature decisions.

\subsubsection{Family dysfunction}

\section{Lack of parental function}

The lack of parental role in the child's development causes the child to bear too much stress in the family that is borne by adults, resulting in a sense of powerlessness and deprivation due to excessive energy expenditure.

In families with dysfunctional parents, children do not have two parents in a normal family and thus do not receive the care they deserve from their families and 
cannot seek help from them when they encounter difficulties. These children generally lack a sense of security and are also prone to character defects and psychological disorders. They are introverted, lonely, emotionally unstable, impulsive and unpredictable. They are not interested in group activities, averse to social interactions, emotionally indifferent, and in severe cases, they may be truant from school, steal, or even prefer violence.

The emotionally instability of parents

The emotional instability of parents affects the stability of the family atmosphere, creating more uncertainty and insecurity in children.

There is a very famous experiment in psychology the expressionless face test (still face experiment). First, the mother and child interact normally with each other and respond enthusiastically to the child's reactions. Next, the mother starts to change her expression from enthusiastic to wooden and expressionless. No matter what the child's response was, the mother's face remained still, empty and unchanged. In just 3 minutes, the child tried various methods - laughing, pointing away, waving her arms, shouting, crying - to get the mother's attention and response, and after repeated failed attempts, the child's expression began to turn helpless, wandering and painful. Finally, when the mother returned to her normal state, the child's emotions were quickly restored. This type of experiment was conducted with children from a variety of cultural backgrounds, and the final consistent conclusion was that changes in the primary parent's response to the child's emotional reactions can have a large impact on the child's emotional development and sense of security.

Family role misplaced

Children have misaligned roles with their parents, become overly involved in their parents' relationships, and take on too much of their parents' emotions. This emotional stress tends to create a sense of powerlessness and emotional and behavioral imbalance in the child.

A family situation with misplaced roles can cause many children to compensate for playing one of those roles as well. Children who should not be playing other roles at a particular age may have to take on the missing part of the role because of the family situation. This situation can cause the child to become knowledgeable beyond his or her own age, and taking on stress beyond his or her own age can mean that the factors that lead to depression in children become more.

\subsection{Internal factors}

\subsubsection{Early traumatic experiences trigger}

Early parental separation
Children are separated from their parents at an early age, and the insecurity caused by this early separation stays with the child and affects the child's connection to parents and others, resulting in a deeper sense of isolation. Restless, sensitive children are more likely to be hurt by such a personality, deepening the possibility of depression.

The rhesus monkey experiment tells us that higher mammals have an innate attachment to their mothers. Moreover, there is a cruel follow-up to this experiment; the young monkeys, deprived of their mother's love from birth and frequently attacked and frightened, grew up with depressive, antisocial, and aggressive tendencies.

Loss of intimate relationship

Children's fear or apprehension of their parents and family due to parental discord or divorce, loss of emotional connection with parents, and lack of intimacy and sense of belonging. This section has a lot in common with family dysfunction and conflict between parents

Verbal or physical violence

Children who grow up with verbal or physical violence by their parents have fearful emotions and physical injuries that leave permanent memories and are frequently triggered, leading to feelings of stress and despair.

Much of the content of verbal violence is damaging to the child's self-esteem, and the child may develop selfdoubt or incurable low self-esteem. After the escalation and abuse of verbal violence, the child develops a selfdestructive mentality and commits even more undesirable behavior or the home education gets out of control.

Studies have shown that children who receive physical violence are more easily disturbed and frightened. In severe cases, they may develop symptoms of PTSD and feel resistant to physical contact. Also, victims of child abuse are more vulnerable to harm in intimate relationships.

\section{SOLUTIONS}

\subsection{Prevention before occurrence}

\subsubsection{Increase the sense of closeness among family members}

John Bowlby's “Attachment Theory" suggests that parents should establish a stable and secure attachment relationship with their children as the base for their children's growth, and attach importance to the interaction and connection of family members' emotions, so that children will have more security and strength to support themselves when they encounter setbacks[9].

The emotional connection between family members is deepened when parents and children do things that they 
can do together (such as family trips, taking family photos, etc.). These things can be based on the child's ideas, with some supplementation and help from the parents. This will give the child the opportunity to take on a leadership role in the family. When children realize their self-worth in the family, they will feel proud of it and become more confident and independent.

\subsubsection{Regular family counseling}

From the family therapy point of view, it is believed that when one person in the family has a serious psychological problem, it is likely that there is a problem in the relationship between family members, and it may be that the interaction between family members maintains the problem, so sometimes it may be that the family whose children are seriously disturbed in their growth and learning come to counseling, and after the counselor's assessment, treatment of only the couple can be effectively improve the symptoms in the child.

\subsubsection{Improve adolescents' ability to cope with themselves[10]}

Studies have shown that adolescents are characterized by volatile mood and impulsive behavior. This leads to the insidious nature of depression in adolescents, and most of them are not diagnosed and treated in time, which is related to the lack of knowledge of the disease among the general public.

Adolescents should be encouraged to take the initiative to learn the skills of self-emotion identification and emotion management, learn positive attribution and effective problem solving, find suitable ways to relieve stress, improve their ability and courage to cope with difficulties and face setbacks, and enhance their psychological flexibility and resilience. For children with interpersonal problems, they are guided to choose the more prominent problems as the focus of attention and continuously follow up to solve them, so as to reduce the degree of depression and improve interpersonal skills.

\subsection{Intervention after occurrence}

\subsubsection{Help your child regain confidence}

Use more encouraging education, offer praise for your child's good behavior, and use encouragement, affirmation, and appreciation as your main attitude. You should have reasonable expectations of your child's learning or abilities, and adjust the level of expectations for your child. In life and learning, see more of the child itself rather than the achievement, and see the child's efforts, dedication and hardships. Parents should listen patiently to their children when communicating with them, put aside their own judgments and values, and take full account of their children's self-esteem and mental capacity.

\subsubsection{Comprehensive education for parents}

As mentioned earlier, many of the family factors that cause depression in children originate from the parents. In communicating with their children, parents should know how to read words and watch their children's facial reactions when they speak. If an obvious emotional change is detected, guide the child to express his or her emotions, rather than dismissing the child's views and feelings out of hand.

Professional organizations should regularly teach parents and help them understand the knowledge related to depression in adolescents. A child's mental state is closely related to many physical states, so it is important to urge the child to maintain a good diet, adequate sleep and regular exercise. Encourage your child to interact more with family and friends to promote good social habits[11].

\section{CONCLUSION}

This paper meticulously presents and deeply analyzes the influence of various family factors (both endogenous and exogenous) on adolescent depression, and proposes measures to address them. The analysis is based on a logical chain of reasoning, mainly based on previous research in the current field, people we know around us or famous cases in the history of psychology, and the author's own experience. However, it needs to be acknowledged that this paper does not present a more novel or therapeutically effective perspective.

\section{REFERENCES}

[1] Sun Kexin. (2021). The Relationship Between Family Socioeconomic Status And Adolescent Depressive Symptoms: The Mediating Role Of Negative Life Events And Their Gender Differences[J], 16(24). Doi: 10.19738/j.cnki.psy.2021.24.004.

[2] Baidu.com user 6931c9b. (2020). The Meaning Of Family Stress Coping Theory ABCX. https://zhidao.baidu.com/question/1670864277162 037067.html

[3] Qunfeng Academy. (2020). Chinese Family Asset Allocation Model. https://www.sohu.com/a/374448619_722231

[4] Ye Xuehua \& Zhang Qiuping \& Wang Jiannv \& Wang Mingxing, A Qualitative Study Of Factors Influencing The Family Developmental Environment Of Children With Adolescent Depression. Zhejiang Provincial Medical and Health Science and Technology Program Project[J], No. 
2020KY745. Nursing and

Rehabilitation,2021,20(09):4-9.

[5] Fan Weichen. (2020). After-school tutoring market size reached 800 billion yuan, parents: classroom fees of 350 yuan per hour(Original title: The extracurricular classes you can't get rid of). https://finance.sina.cn/chanjing/gdxw/2020-0831/detail-iivhvpwy3987932.d.html?cref $=$ cj

[6] Southern Metropolis Daily. (2020). Southern Metropolis Daily Poll Shows That High Academic Pressure Is The Leading Cause Of Psychological Distress Among Children And Adolescents. https://www.sohu.com/a/436938935_161795

[7] News Desk. (2020). Controlling Parents Give Their Kids Depression, Study Shows. https://theworld.org/stories/2013-02-13/controllingparents-give-their-kids-depression-study-shows

[8] Isabell Schuster, Pathways from Child Sexual and Physical Abuse to Sexual and Physical Intimate Partner Violence Victimization through Attitudes toward Intimate Partner Violence. Aug.1st, 2020. Journal of Family Violence. https://www.xmol.com/paper/1340010951337492480/t?recomme ndPaper $=1340011125984116736$

[9] Dr. Saul McLeod. (2017). Bowlby's Attachment Theory.

https://www.simplypsychology.org/bowlby.html

[10] American Academy of Pediatrics, Adolescent Depression: What Parents Can Do To Help? Adapted from Addressing Mental Health Concerns in Primary Care: A Clinician?s Toolkit (Copyright (C) 2010 American Academy of Pediatrics). Feb.26th, 2018. https://www.healthychildren.org/English/healthissues/conditions/emotionalproblems/Pages/Childhood-Depression-WhatParents-Can-Do-To-Help.aspx

[11] Wang Xiaoting, Current Anxiety And Depression Problems Of Adolescents And Suggestions. Fine Culture; Fine Arts[J]. Reading Digest,2019(09):31. 